University of Nebraska - Lincoln

DigitalCommons@University of Nebraska - Lincoln

Publications from USDA-ARS / UNL Faculty

U.S. Department of Agriculture: Agricultural

Research Service, Lincoln, Nebraska

2008

\title{
Volatile compounds from the integument of White Leghorn \\ Chickens (Gallus gallus domesticus L.): Candidate attractants of ornithophilic mosquito species
}

\author{
Ulrich R. Bernier \\ University of Florida, ubernier@gainesville.usda.ufl.edu \\ Sandra A. Allan \\ USDA-ARS, sandy.allan@ars.usda.gov \\ Brian Quinn \\ United States Department of Agriculture \\ Daniel Kline \\ United States Department of Agriculture \\ Donald Barnard \\ United States Department of Agriculture
}

See next page for additional authors

Follow this and additional works at: https://digitalcommons.unl.edu/usdaarsfacpub

Part of the Agricultural Science Commons

Bernier, Ulrich R.; Allan, Sandra A.; Quinn, Brian; Kline, Daniel; Barnard, Donald; and Clark, Gary, "Volatile compounds from the integument of White Leghorn Chickens (Gallus gallus domesticus L.): Candidate attractants of ornithophilic mosquito species" (2008). Publications from USDA-ARS / UNL Faculty. 967. https://digitalcommons.unl.edu/usdaarsfacpub/967

This Article is brought to you for free and open access by the U.S. Department of Agriculture: Agricultural Research Service, Lincoln, Nebraska at DigitalCommons@University of Nebraska - Lincoln. It has been accepted for inclusion in Publications from USDA-ARS / UNL Faculty by an authorized administrator of DigitalCommons@University of Nebraska - Lincoln. 


\section{Authors}

Ulrich R. Bernier, Sandra A. Allan, Brian Quinn, Daniel Kline, Donald Barnard, and Gary Clark 


\section{Ulrich R. Bernier \\ Sandra A. Allan \\ Brian P. Quinn \\ Daniel L. Kline \\ Donald R. Barnard \\ Gary G. Clark}

United States Department of Agriculture, Agricultural

Research Service, Center for Medical, Agricultural, and Veterinary Entomology,

Gainesville, FL, USA

\section{Original Paper}

\section{Volatile compounds from the integument of White Leghorn Chickens (Gallus gallus domesticus L.): Candidate attractants of ornithophilic mosquito species*}

\begin{abstract}
Candidate kairomones of ornithophilic mosquito species are reported from GC/MS analysis of compounds from the skin on the back, the feet, and feathers from the back of White Leghorn chickens (Gallus gallus domesticus). Hexane and ether extracts of chicken feathers differ significantly in attractiveness of Culex spp. mosquitoes. The active (hexane) extracts contained an abundance of alcohols, ketones, and diones. The inactive (ether) extracts contained aldehydes, which also were in the hexane extracts. Analysis of hexane extracts from chicken feet, skin, and feathers demonstrated the qualitative similarity in the compounds collected with subtle differences observed in the quantitative amounts of these compounds. Aldehydes and carboxylic acids were detected in a concentrated ether extract of feathers in quantitatively similar ratios within each compound class for the corresponding series of $\mathrm{C}_{6}-$ $\mathrm{C}_{9}$ aldehydes and acids.
\end{abstract}

Keywords: Bird odors / Extracts / GC/MS / Kairomones / Semiochemicals

Received: September 11, 2007; revised: December 29, 2007; accepted: December 30, 2007

DOI 10.1002/jssc.200700434

\section{Introduction}

Mosquitoes are vectors of pathogens to humans and other vertebrates, resulting in significant disease transmission worldwide. On a global scale, malaria transmitted by Anopheles spp. and dengue and yellow fever transmitted by Aedes spp. are common diseases transmitted by mosquitoes to humans [1, 2]. Mosquito-borne illnesses in the US are typically the encephalitides or West Nile virus transmitted primarily by Culex spp., although other genera also are competent vectors. The domestic mosquito species that are primarily involved in disease transmission are $C x$. pipiens pipiens (L.), $C x$. nigripalpus Theobald, $C x$. tarsalis Coquillett, and $C x$. pipiens quinquefasciatus Say. As reported by McIver [3] for Cx. tarsalis, these mosquitoes exhibit a strong host preference for birds. They transmit their pathogens to humans through opportunistic feeding after a blood meal has been taken from an infected bird.

Mosquito host selection is influenced heavily by the odors, including carbon dioxide, that are emanated by the host [4]. Anthropophilic mosquitoes are highly attracted in laboratory bioassays to odors identified from

Correspondence: Dr. Ulrich R. Bernier, USDA-ARS-CMAVE, 1600 SW 23rd Drive, Gainesville, FL 32608, USA E-mail: ubernier@gainesville.usda.ufl.edu Fax: +1-352-374-5922 human skin $[5,6]$. Host discrimination is believed to be based primarily on chemical cues since lipids on the skin surface of humans differ significantly from those of other animals including birds. Considerable effort has been expended in identifying these compounds on humans, other animals, and birds including the domestic chicken [7-17].

Some of the studies of bird odors focus on uropygial gland secretions, skin emanations, and volatile compounds from feathers to isolate and identify kairomones used for host location by biting flies and mosquitoes [18-21]. Extracts of the loon and duck, especially ether extracts of the tail region, attract black flies (Simuliidae) [18]. Secretions from uropygial glands of crows enhance the collection of Culex spp. when added to a trap, provided that trap placement is at the proper height [19]. The work of Williams et al. [20] combined chemical analysis and bioassays to identify compounds that mediate host-seeking behavior of Culex annulirostris Skuse, a mosquito found in Australia and nearby regions surrounding the Australian continent. They employed solid phase microextraction (SPME) fibers to concentrate emana-

\footnotetext{
* This paper reports the results of research only. Mention of a chemical compound does not constitute an endorsement for use by the USDA, nor does it imply registration under FIFRA as amended.
} 
tions for subsequent GC/MS identification both from solvent extraction of the fur or feathers and from concentration of volatiles in the headspace. In that study, odors produced by guinea pigs and chickens were identified as candidate attractants for testing in laboratory and field bioassays. An interesting result from the study was that isolated populations of the same mosquito species exhibit dissimilar host preferences (avian/chicken compared to guinea pig), suggesting microevolutionary changes in host chemical preferences.

Allan et al. [21] chose a different approach, where solvent extracts from White Leghorn hens were tested for biological activity against several ornithophilic mosquito species. It was established that the hexane extract contained the attractive volatiles to the Culex spp., whereas the ether extract was not attractive. Although the ether extract was not tested for allomonal compounds, it is quite possible that one or more of these compounds, e.g., aldehydes and particularly nonanal, may suppress mosquito host seeking [22-24]. We report here the chemical analyses of samples used to investigate the differential attractiveness between the extracts and examine to what extent differences are observed in compounds collected from different anatomical regions of the chicken. We also report some similarities in the abundance ratios of compounds among the $\mathrm{C}_{6}-\mathrm{C}_{9}$ aldehydes and carboxylic acids that are present. A similar pattern was noticed in studies of human odors, but the components were not quantified [5].

\section{Materials and methods}

\subsection{Solvent collections}

Sample collection as from adult White Leghorn hens was performed as approved in projects D207 and D469 and by the University of Florida Institutional Animal Care and Use Committee (Gainesville, FL). Hands were gloved with powder-free Latex examination gloves (Microflex, Reno, NV) to prevent contamination of samples with human skin emanations. Feather samples were collected by clipping from the side and back of the chicken. After collection of $\sim 10 \mathrm{~g}$ of feathers, the feathers were transferred into a glass funnel that contained a glass wool filter. A volume of $20 \mathrm{~mL}$ of solvent was passed through the feathers and collected in a $20 \mathrm{~mL}$ scintillation vial (Kimble Glass, Vineland, NJ). Feet extracts were obtained by rinsing the feet with $5 \mathrm{~mL}$ of solvent and recollecting the solvent in a $20 \mathrm{~mL}$ scintillation vial (Kimble Glass). Skin extracts were obtained using $5 \mathrm{~mL}$ of solvent dripped across a $\sim 36 \mathrm{~cm}^{2}$ shaved (featherless) area of skin on the back of the chicken and the solution was recollected in a $20 \mathrm{~mL}$ scintillation vial. Samples were collected in triplicate over a $2 \mathrm{wk}$ period (two collections in one week and one collection the following week). All extracts were con- centrated to $200 \mu \mathrm{L}$ using an N-Evap 111 Nitrogen Evaporator (Organomation Associates, Berlin, MA). An ether extract of feathers was further concentrated to $\sim 20 \mu \mathrm{L}$ for injection and separation on a free fatty acid polar column.

\subsection{Reagents}

The solvents used were ReagentPlus ( $\geq 99.9 \%$ ) hexane and Spectrophotometric grade (99.9\%) diethyl ether (Sigma-Aldrich, Milwaukee, WI). Standards used for confirmation of compounds (3-hexanol, 2-hexanol, 3-hexanone, 2-hexanone, 2,5-hexanedione, 3,4-hexanedione, nonanal, hexanal, and benzaldehyde) were also obtained from Sigma-Aldrich.

\section{$2.3 \mathrm{GC} / \mathrm{MS}$}

The gas chromatography/mass spectrometry (GC/MS) system used was a ThermoFinnigan Trace GC/MS single quadrupole system (Thermo Fisher Scientific, Waltham, MA). Prior to analysis of samples, the instrument was tuned and calibrated with perfluorotributylamine. Solvent blanks (hexane or diethyl ether) were concentrated and analyzed to identify contaminants. The blanks were analyzed as described for the samples. Compounds present in the blank analyses were excluded from the composition percentages of compounds in the samples.

Comparison of collections with hexane and ether solvents and hexane collection from different surfaces of the chicken were conducted using the GC equipped with a $30 \mathrm{~m} \times 0.25 \mathrm{~mm}$ id $(\mathrm{df}=0.25 \mu \mathrm{m})$ DB-Waxetr column (Agilent Technologies, Wilmington, DE). The split/splitless injector was set to $260^{\circ} \mathrm{C}$ and operated in splitless mode $(1.00 \mathrm{~min})$ with a surge pressure of 4.35 psi for $1.00 \mathrm{~min}$. The injection port was operated in constant flow mode at an initial rate of $1.20 \mathrm{~mL} / \mathrm{min}$ He carrier gas and dropped to $1.00 \mathrm{~mL} / \mathrm{min}$ after $1.00 \mathrm{~min}$. The GC oven was programed to be held at $35^{\circ} \mathrm{C}$ for $6.00 \mathrm{~min}$ after injection, then ramped at $10^{\circ} \mathrm{C} / \mathrm{min}$ to $260^{\circ} \mathrm{C}$, and held at that final temperature for $5.00 \mathrm{~min}$.

For the analysis of a concentrated diethyl ether extract to examine the proportions of aldehydes and acids, the column was a $30 \mathrm{~m} \times 0.25 \mathrm{~mm}$ id $(\mathrm{df}=0.25 \mu \mathrm{m})$ DB-FFAP column (Agilent Technologies). This column has a lower temperature limit $\left(245^{\circ} \mathrm{C}\right)$, therefore, the $\mathrm{GC}$ oven ramp was modified. In this case, the initial hold was for $5.00 \mathrm{~min}$ at $35^{\circ} \mathrm{C}$, followed by a $6.0^{\circ} \mathrm{C} / \mathrm{min}$ ramp to $245^{\circ} \mathrm{C}$, and a final hold at that temperature for $10.00 \mathrm{~min}$. The injection port was operated as described above for the DB-Waxetr column.

The mass spectrometer was operated in electron ionization (EI) mode using the dedicated EI source, scanned over a mass range of $m / z 35-550$ at a rate of 0.5 s per scan. The emission current was set at $350 \mu \mathrm{A}$, detector voltage 


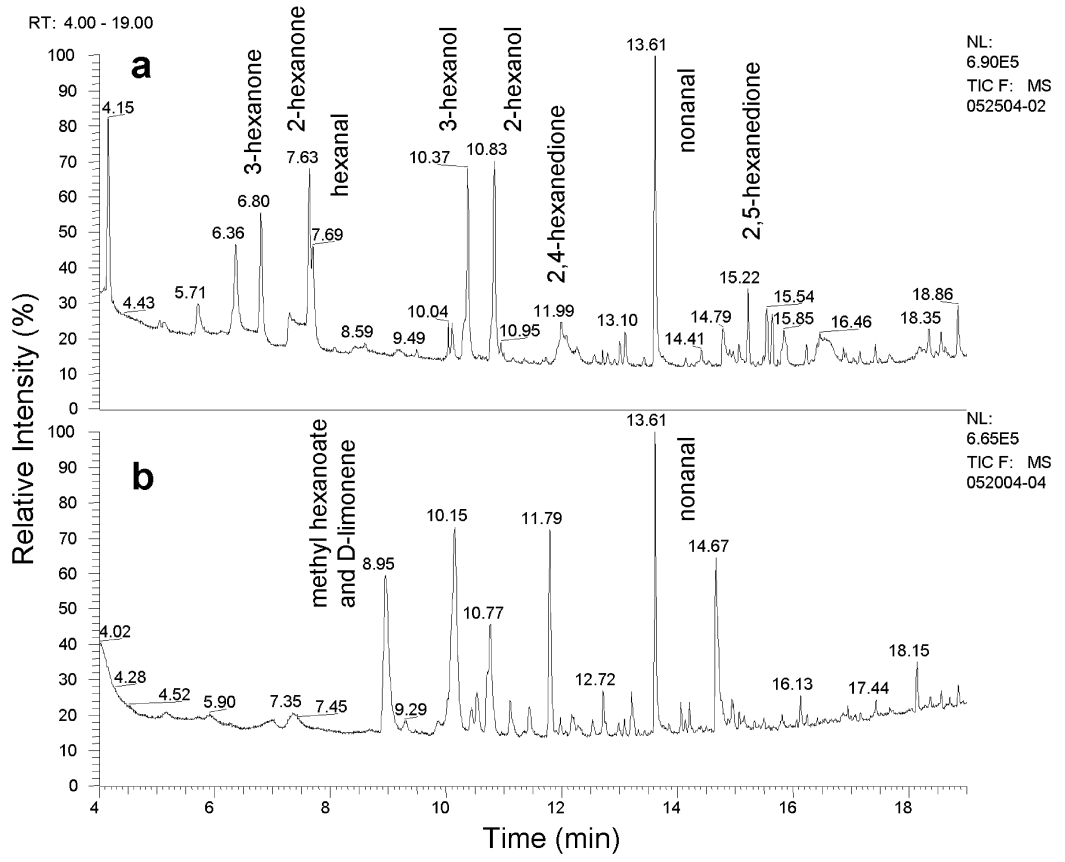

Figure 1. Chromatograms of (a) hexane extract and (b) diethyl ether extracts from $10 \mathrm{~g}$ of feathers collected from a domestic chicken. Separation is effected by a $30 \mathrm{~m} \times 0.25 \mathrm{~mm}$ id $(\mathrm{df}=0.25 \mu \mathrm{m})$ DB-Waxetr column. Chromatogram (a) is from injection of the biologically active (attractive) extract and chromatogram (b) elicits no attraction from mosquitoes. was set at $300 \mathrm{~V}$, and the source temperature was set at $200^{\circ} \mathrm{C}$. The transfer line temperature was maintained at $260^{\circ} \mathrm{C}$ for the DB-Wax column and at $245^{\circ} \mathrm{C}$ when the FFAP column was installed. Typical results from the replicated samples are shown in figures and tables.

\section{Results and discussion}

Avian uropygial glands generally are thought to waterproof the plumage or inhibit microbial growth [24]. Secretions from this gland are spread over the plumage while preening. This gland is the only prominent integumentary gland found on these birds. The secretions of this gland in chickens contain long chain diols [12]. Lipids from the uropygial gland of chickens are likely not sufficiently volatile to factor significantly in the mosquito host-finding process. Instead, the microbial breakdown products of surface lipids including those derived from uropygial glands are more likely the volatile compounds that serve as kairomones for host location of blood-feeding mosquitoes. Presumably, all compounds detected by mosquitoes are either from microbial degradation of the uropygial diols or from exogenous deposition via contact with foreign substances.

Figure 1 illustrates the differences in composition of the hexane (Fig. 1a) and diethyl ether (Fig. 1b) extracts of chicken feathers. Although these chromatograms depict a single run for each extract, the constituents of replicated extract analyses were all similar, with minor differences in percentages observed primarily for trace constituents. Table 1 contains the full listing of components over the displayed range of chromatograms in Fig. 1; it lists compounds compiled by retention time $\left(t_{\mathrm{R}}\right)$, tentative (or confirmed) identifications, and percentage composition based upon counts of peak area. Although the ranges and RSDs are not reported in the table, major constituents typically exhibited RSDs of $<2 \%$. For example, the quantitative percentage ranges for 2-hexanone and 3hexanone in the triplicate collections were $8.8-11.1 \%$ and $9.4-11.7 \%$, respectively. The main difference observed between the chromatograms of these two extracts resides in the ketones and alcohols detected. The hexane extract contains both 2-hexanone and 3-hexanone, and 2-hexanol and 3-hexanol, whereas the ether extract does not. The production of similar alcohols and ketones is known to occur either through oxidation from alcohol to ketone [25], or from reduction of ketone to the alcohol [26]. In both cases, the processes involve yeast. A similar chemical conversion may occur on the skin of chickens, resulting in production of these ketones from oxidation of alcohols. We presume that uropygial gland diols are initially broken down to these alcohols, but we are not aware of any corroborating data to support this hypothesis.

As is apparent from Table 1, the relative proportions of these alcohols and ketones within the sample are approximately equal. Note that the percentage composition is calculated after exclusion of peak area counts of those peaks present in the blanks. Two diones, 2,4-hexanedione (enol) and 2,5-hexanedione were also identified. The 2,5hexanedione was identified by matching with a library mass spectrum and by comparison of retention time to that of the commercially available standard. This dione 
Table 1. Compounds and their percentage compositions in hexane and ether extracts of chicken feathers from a White Leghorn chicken

\begin{tabular}{|c|c|c|c|}
\hline \multirow[t]{2}{*}{$t_{\mathrm{R}}(\min )$} & \multirow[t]{2}{*}{ Compound } & \multicolumn{2}{|c|}{ Composition $(\%)$} \\
\hline & & Hexane & Ether \\
\hline 4.15 & Unknown branched alcohol & 12.1 & \\
\hline 5.71 & Octamethyl cyclotetrasiloxane ${ }^{\text {a) }}$ & & \\
\hline 6.36 & Toluene $^{\mathrm{a})}$ & & \\
\hline 6.80 & 3-Hexanone ${ }^{\mathrm{b})}$ & 10.0 & \\
\hline 7.63 & 2-Hexanone ${ }^{\text {b) }}$ & 10.2 & \\
\hline 7.69 & Hexanal $^{\text {b) }}$ & 6.9 & \\
\hline 8.95 & Methoxyflurane $^{\text {a) }}$ & & \\
\hline 9.86 & p-Xylene & & 1.3 \\
\hline 10.04 & Decamethyl cyclopentasiloxane ${ }^{\text {a) }}$ & & \\
\hline 10.10 & Heptanal & 1.6 & 2.1 \\
\hline 10.15 & Methyl hexanoate/D-limonene & & 19.0 \\
\hline 10.37 & 3-Hexanol ${ }^{\text {b) }}$ & 8.7 & \\
\hline 10.43 & Propylbenzene & & 2.5 \\
\hline 10.55 & Diethyl disulfide & & 3.5 \\
\hline 10.77 & 1-Ethyl-4-methylbenzene & & 6.9 \\
\hline 10.83 & 2-Hexanol ${ }^{\text {b) }}$ & 10.1 & \\
\hline 10.95 & 1-Methylcyclopentanol & 0.5 & \\
\hline 10.99 & 2-Pentylfuran & 0.1 & \\
\hline 11.11 & 1,3,5-Trimethylbenzene & & 3.8 \\
\hline 11.44 & 1,2,4-Trimethylbenzene & & 2.5 \\
\hline 11.73 & 3-Hexen-1-ol & 0.5 & \\
\hline 11.79 & 1,2,3-Trimethylbenzene & & 16.3 \\
\hline 11.98 & Octanal & 0.8 & 1.1 \\
\hline 11.99 & 2,4-Hexanedione (enol) & 1.2 & \\
\hline 12.17 & 1-Methyl-4-propylbenzene & & 1.9 \\
\hline 12.54 & 1-Methyl-3-propylbenzene & & 1.2 \\
\hline 12.56 & 2-Heptenal & 0.4 & \\
\hline 12.72 & Substituted benzene & & 2.5 \\
\hline 13.01 & 1-Hexanol & 1.2 & \\
\hline 13.10 & Unknown, possibly furan & 1.7 & \\
\hline 13.61 & Nonanal $^{b)}$ & 18.6 & 17.8 \\
\hline 14.70 & Acetic acid & 3.5 & 14.9 \\
\hline 14.76 & Substituted benzene & & 0.3 \\
\hline 15.08 & Decanal & 0.7 & 0.6 \\
\hline 15.22 & 2,5-Hexanedione ${ }^{\text {b) }}$ & 3.5 & 0.5 \\
\hline 15.48 & Benzaldehyde & 0.3 & 0.8 \\
\hline 15.54 & Unknown methyl branched alcohol & 2.7 & \\
\hline 15.64 & Unknown & 2.5 & \\
\hline 15.85 & Propanoic acid & 2.1 & 0.4 \\
\hline 16.13 & DMSO & & \\
\hline 18.15 & Napthalene $e^{\text {a) }}$ & & \\
\hline
\end{tabular}

Relative compositions are reported after exclusion of compounds determined to be contaminants.

a) Compound present in blank solvent samples.

b) Tentative identification confirmed by injection of commercial standard.

was reported by Williams et al. [20] as a volatile produced from guinea pigs but was not detected in their collections from chicken feathers. The presence of 2,5-hexanedione, a metabolite found in human urine that arises from exposure to hexane, is of concern because of its association with polyneuropathy [27]. Another report has recently documented the presence of other diones from reptiles, specifically novel ethyl-branched diones from the paracloacal glands of crocodylians [28].
This is the first report of 2,4-hexanedione (enol) as a tetrapod skin product. A 2,4-hexanedione (enol) standard was not available for comparison with the native component; however, interpretation of this and other mass spectra strongly favored this assignment. A standard of 3,4-hexanedione was examined, but the retention time nor the mass spectrum matched that of the peak identified as 2,4-hexanedione (enol) (the $\mathrm{m} / \mathrm{z} 85$ ion is absent in this mass spectrum). Since this peak eluted prior to that 


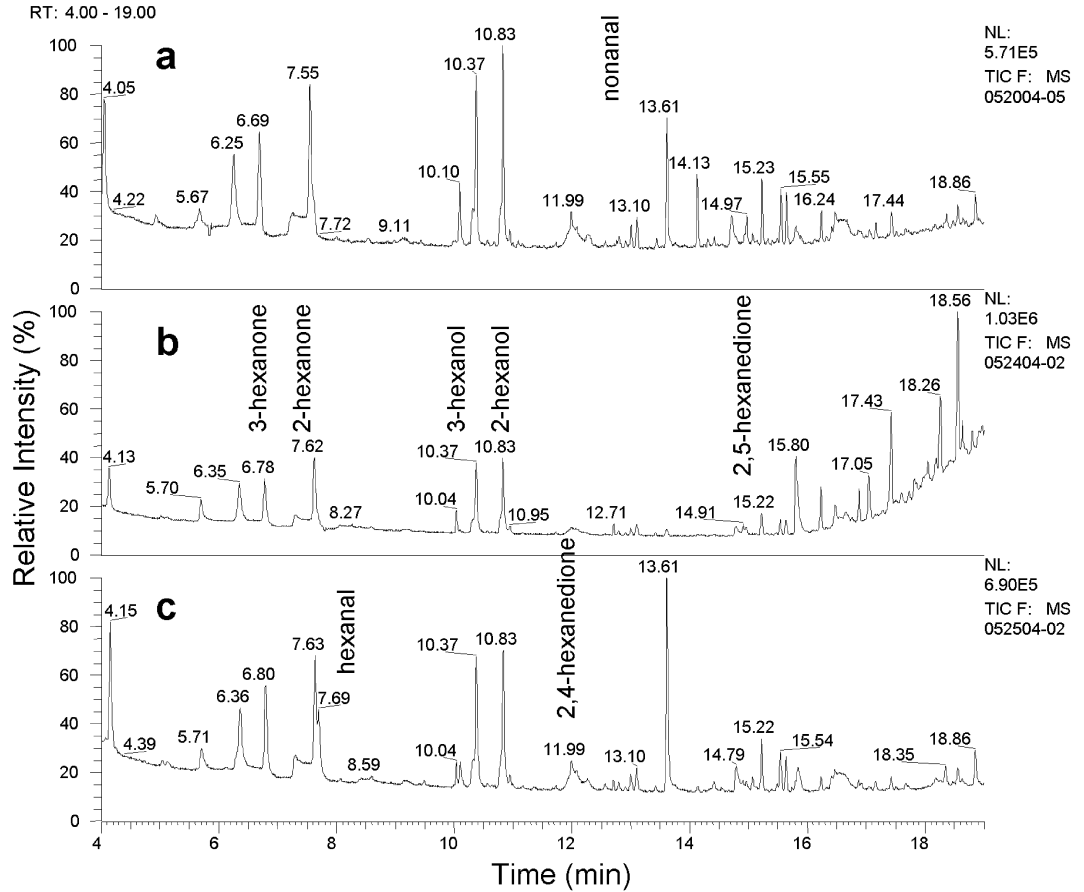

Figure 2. Chromatograms of hexane extracts from (a) feet, (b) skin, and (c) feathers of a single domestic chicken. Feet and skin samples are collected by extracting the foot, or a shaved section of the side of a chicken. Feather samples are collected from $10 \mathrm{~g}$ of feathers as the starting material. Separation is effected by a $30 \mathrm{~m} \times 0.25 \mathrm{~mm}$ id $(\mathrm{df}=0.25 \mu \mathrm{m})$ DB-Waxetr column. of 2,5-hexanedione, it was possible that this compound could be 2,4-pentanedione. However, the mass spectrum of this compound produces an $\mathrm{M}^{+}$(molecular) ion of $m / z 100$, which does not account for the $m / z 114 \mathrm{M}^{+} \bullet$ ion observed in the mass spectrum of 2,4-hexanedione (enol).

Aldehydes were detected in hexane and ether extracts, with nonanal being the most abundant. Hexanal, benzaldehyde, and nonanal have been reported previously from both chicken feathers and guinea pig hair [20]. In addition to hexanal, we detected other aldehydes including heptanal, octanal, decanal, and benzaldehyde. Hexanal, benzaldehyde, and nonanal failed to attract $C x$. quinquefasciatus in laboratory assays [21]. Puri et al. [29] reported that some aldehydes elicit electroantennographic responses in $C x$. quinquefasciatus, and in that nonanal was attractive [29]. Benzaldehyde, however, had no effect.

Some of the compounds we observed in chicken extracts were unexpected including compounds deemed to be contaminants and others known to be present from other living sources. For example, the occurrence of methoxyflurane was easily explained once we noticed that this reagent was stored next to the one of the stock bottles of ether used in these experiments. In contrast, the compound 2-pentylfuran is also present in human odors [5] and has been detected in chicken feather hydrolysate [30]. We detected this compound in headspace purge and trap GC/MS analysis (unpublished data).

The collection of feather extracts is a less complex collection method than the collection of solvent passed over the feet and skin of a chicken, i.e., one can measure a mass of feathers and achieve collection with little extraneous solvent loss other than absorption. Collections from skin and feet are complicated by various factors such as evaporation of solvent from the surface and dermal absorption [31]. However, mosquitoes that take a blood meal from chickens do so through the skin. Therefore, if collections from the feathers contain similar compounds to those from feet and skin, the feathers are the better option for study.

The chromatograms for compounds from hexane extracts of feet (Fig. 2a), skin (Fig. 2b), and feathers (Fig. 2c) illustrate the similarity of compounds present, particularly among the most volatile compounds observed using these collection methods. Some minor apparent differences in compound abundances are apparent evident in the chromatograms, e.g., the difference in the ratio of nonanal (13.61 $\mathrm{min})$ to 3-hexanol or 2-hexanol (10.37, $10.83 \mathrm{~min})$ in Fig. 2a compared to 2c. Additional compounds of greater abundance in the less volatile region $\left(t_{R}>16 \mathrm{~min}\right.$ ) are easily seen in the skin wash (Fig. $2 \mathrm{~b})$, however, based on the lower volatility of these, they are less likely to act as cues for host-seeking by mosquitoes.

Table 2 features the retention times and percentage composition of compounds for each extract in the chromatograms of Fig. 2. The compounds and relative proportions of these within each sample are similar for feet, skin, and feathers. Although most of the compounds listed in Table 2 are identical to those in Table 1, there are some differences. Among these are 1-methylcyclopentanol and 2-furanmethanol, both thought to be endoge- 
Table 2. Compounds and their percentage compositions in hexane solvent collections from the feet, skin, and feathers of a White Leghorn chicken

\begin{tabular}{|c|c|c|c|c|}
\hline \multirow[t]{2}{*}{$t_{\mathrm{R}}(\min )$} & \multirow[t]{2}{*}{ Compound } & \multicolumn{3}{|c|}{ Composition (\%) } \\
\hline & & Feet & Skin & Feathers \\
\hline 4.15 & Unknown branched alcohol & 7.9 & 4.3 & 9.5 \\
\hline 5.00 & Decane & 1.1 & 0.5 & 0.5 \\
\hline 5.71 & Octamethyl cyclotetrasiloxane ${ }^{a)}$ & & & \\
\hline 6.36 & Toluene $^{\text {a) }}$ & & & \\
\hline 6.80 & 3-Hexanone ${ }^{\text {b) }}$ & 10.1 & 6.6 & 7.8 \\
\hline 7.63 & 2-Hexanone ${ }^{\text {b) }}$ & 17.4 & 11.7 & 17.2 \\
\hline 7.69 & Hexanal $^{\text {b) }}$ & 3.0 & 1.3 & 5.0 \\
\hline 10.04 & Decamethyl cyclopentasiloxane & & & \\
\hline 10.10 & Heptanal & 3.2 & 0.4 & 1.6 \\
\hline 10.37 & 3-Hexanol ${ }^{\text {b) }}$ & 11.9 & 9.0 & 11.3 \\
\hline 10.83 & 2-Hexanol ${ }^{\text {b) }}$ & 12.2 & 9.6 & 11.2 \\
\hline 10.95 & 1-Methylcyclopentanol & 0.6 & 0.6 & 0.6 \\
\hline 11.73 & 3-Hexen-1-ol & 0.2 & 0.2 & 0.3 \\
\hline 11.99 & 2,4-Hexanedione (enol) & 2.1 & 0.8 & 1.9 \\
\hline 12.71 & Dodecamethyl cyclohexasiloxane ${ }^{\mathrm{a})}$ & & & \\
\hline 13.01 & 1-Hexanol or methylpentanol? & 0.8 & 0.6 & 0.8 \\
\hline 13.10 & Unknown & 1.5 & 1.0 & 1.4 \\
\hline 13.42 & Unknown ${ }^{\text {a) }}$ & & & \\
\hline 13.61 & Nonanal $^{\text {b) }}$ & 6.4 & 0.6 & 14.9 \\
\hline 14.13 & Hexachloroethane (Avlothane) & 3.1 & 0.1 & \\
\hline 14.31 & Unknown, terpene? & 0.3 & & \\
\hline 14.42 & Unknown, possibly alcohol? & 0.4 & 0.2 & 0.4 \\
\hline 14.78 & Acetic acid & 2.9 & 1.2 & 2.8 \\
\hline 14.97 & Pentadecane & 1.0 & 0.5 & 0.2 \\
\hline 15.08 & Decanal & 0.5 & 0.2 & 0.6 \\
\hline 15.22 & 2,5-Hexanedione ${ }^{\mathrm{b})}$ & 2.9 & 1.9 & 2.8 \\
\hline 15.48 & Benzaldehyde & 0.1 & 0.3 & 0.2 \\
\hline 15.54 & Unknown methyl branched alcohol & 2.6 & 1.2 & 2.1 \\
\hline 15.64 & Unknown & & 1.2 & \\
\hline 15.80 & Propanoic acid ${ }^{\text {a) }}$ & & & \\
\hline 16.23 & Hexadecane & 1.4 & 3.5 & 0.6 \\
\hline 16.41 & Undecanal? & 0.3 & 0.3 & 0.5 \\
\hline 16.47 & Unknown, possibly ketone? & 1.6 & 2.1 & 0.7 \\
\hline 16.88 & $\begin{array}{l}\text { Hexadecamethyl cyclo- } \\
\text { octasiloxane }^{\text {a) }}\end{array}$ & & & \\
\hline 17.05 & Unknown branched hydrocarbon & 0.5 & 4.6 & 0.2 \\
\hline 17.16 & 2-Furanmethanol & & & \\
\hline 17.44 & Unknown hydrocarbon & 1.2 & 9.5 & 0.6 \\
\hline 18.26 & Unknown hydrocarbon & & 8.4 & 0.2 \\
\hline 18.35 & Unknown & 0.5 & & 1.1 \\
\hline 18.56 & Unknown hydrocarbon & 0.8 & 17.6 & 0.8 \\
\hline 18.86 & Unknown aldehyde & 1.4 & & 2.1 \\
\hline
\end{tabular}

Relative compositions are reported after exclusion of compounds determined to be contaminants.

a) Compound present in blank solvent samples.

b) Tentative identification confirmed by injection of commercial standard.

nous products. Another compound likely to be exogenous is hexachloroethane, which was detected primarily on the feet and some on the skin. This compound may be present in some fungicides and insecticides and is used for deworming. Finally, a number of unknown components appear to be unsaturated alcohols.

Our final analysis was performed on a highly concentrated ether extract of feathers. Our results indicate that not only was there similarity in abundances of ketones and alcohols on feathers (see Fig. 1a), but also the pat- terns of aldehydes and abundances compared to acids were similar. Since hexanal coeluted with 2-hexanone in the hexane extracts, and with knowledge that the aldehydes were present in hexane and ether extracts, an ether rinse of feathers was selected for additional concentration and analysis. An FFAP column was employed to separate these acids and aldehydes, as shown in Fig. 3. Table 3 presents the retention times, with each of the $\mathrm{C}_{6}-\mathrm{C}_{9}$ aldehydes and acids, followed by the percentage composition of each of these within their respective com- 


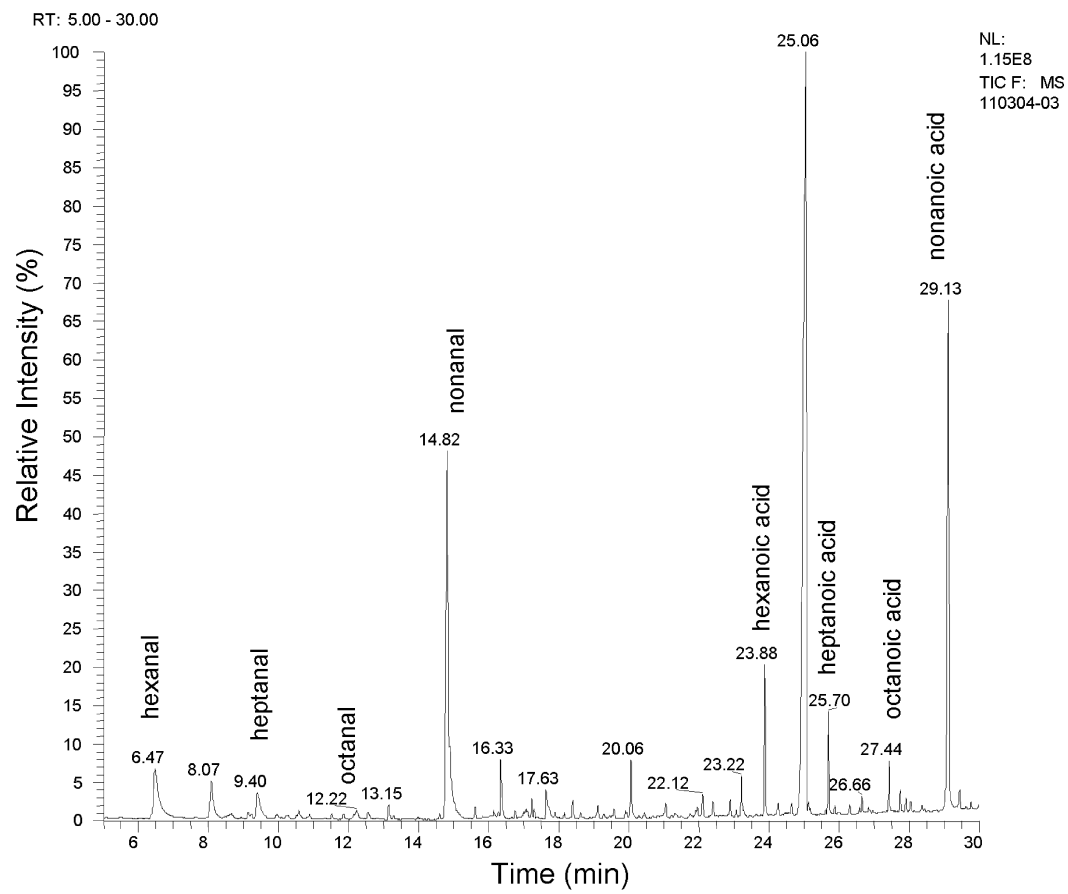

Figure 3. Concentrated ether extract of $10 \mathrm{~g}$ chicken feathers, evaporated under nitrogen to $\sim 0.1 \mathrm{~mL}$. Chromatography conducted with a $30 \mathrm{~m} \times 0.25 \mathrm{~mm}$ id $(\mathrm{df}=0.25 \mu \mathrm{m})$ DB-FFAP column.

Table 3. Comparison of relative percentage composition within the ether-extracted aldehydes from feathers and the similarity to the percentage composition of extracted acids in the same sample

\begin{tabular}{rlcllr}
\hline$t_{\mathrm{R}}(\mathrm{min})$ & Compound & Comp $(\%)$ & $t_{\mathrm{R}}(\mathrm{min})$ & Compound & Comp $(\%)$ \\
\hline 6.47 & Hexanal & 23 & 23.88 & Hexanoic acid & 14 \\
9.40 & Heptanal & 7 & 25.70 & Heptanoic acid & 9 \\
12.23 & Octanal & 2 & 27.44 & Octanoic acid & 4 \\
14.82 & Nonanal & 68 & 29.13 & Nonanoic acid & 73 \\
\hline
\end{tabular}

These data were collected after additional concentration of the ether extract and separation on a free fatty acid polar (FFAP) column to better resolve these compounds.

pound classes. The similarity in the abundances of these compounds relative to each other within a compound class is noteworthy. It may indicate a similar origin of these compounds from microbial degradation of the surface chemicals of the feathers, feet, or skin.

In contrast to human emanations, the number of compounds present from chickens is much fewer. One possible reason for the difference is the significant difference in skin chemistry of mammals compared to reptiles, which includes birds [8]. With respect to the number of volatile to semivolatile emanations, we have found that compounds present on the skin of other mammals, such as ungulates and a carnivore (the Florida panther), also contain much fewer volatiles on the skin than do humans (U.R.B., unpublished results).

\section{Concluding remarks}

The availability of biologically active and inactive extracts has facilitated the identification of compounds in the active extract that may be cues for host location. These compounds are currently undergoing biological assays alone and in blends as kairomones for ornithophilic mosquitoes. Volatile aldehydes were also identified in both extracts and are therefore less likely to play a substantial role as kairomones, but could perhaps impact the overall host-seeking behavior by another mechanism, e.g., allomonal action resulting in host avoidance. Finally, the similarities in abundances between ketones and alcohols, ketones and diones (Figs. 1 and 2), and the aldehydes and acids (Fig. 3) may indicate that similar microbial degradation pathways produce these compounds on the surface of chickens.

\section{References}

[1] Goddard, J., Physician's Guide to Arthropods of Medical Importance, 2nd Edn., CRC Press, Boca Raton, FL 1996, pp. 221- 230.

[2] Gillett, J. D., Mosq. News 1979, 39, 221-229.

[3] McIver, S. B., J. Med. Entomol. 1968, 5, 422-428. 
[4] Takken, W., Insect Sci. Appl. 1991, 12, 287-295.

[5] Bernier, U. R., Kline, D. L., Barnard, D. R., Schreck, C. E., Yost, R. A., Anal. Chem. 2000, 72, 747-756.

[6] Bernier, U. R., Kline, D. L., Posey, K. H., Booth, M. M., Yost, R. A. Barnard, D. R., J. Med. Entomol. 2003, 40, 653-656.

[7] Nicolaides, N., Science 1974, 186, 19-26.

[8] Nicolaides, N., Fu, H. C., Rice, G. R., J. Invest. Derm. 1968, 51, 83 89

[9] Wertz, P. W., Stover, P. M., Abraham, W., Downing, D. T., J. Lipid Res. 1986, 27, 427- 435 .

[10] Nicolaides, N., Fu, H. C., Ansari, M. N. A., Lipids 1970, 5, 299-307.

[11] Haati, E. O. A., Fales, H. M., J. Lipid Res. 1967, 8, 131-137.

[12] Haati, E., Lagerspetz, K., Nikkari, T., Fales, H. M., Comp. Biochem. Physiol. 1964, 12, $435-437$.

[13] Tang, B. Y., Hansen, I. A., Comp. Biochem. Physiol. 1976, 54B, 483 488.

[14] Kolattukudy, P. E., Sawaya, W. N., Lipids 1974, 9, $290-292$.

[15] Walker, H. E., Somes, R. G., Jr., Lipids 1978, 13, 492- 496.

[16] Jacob, J., in: Kolattukudy, P. E. (Ed.), Chemistry and Biochemistry of Natural Waxes, Elsevier, New York 1976, pp. 93-146.

[17] Buckner, J. S., Kolattukudy, P. E., in: Kolattukudy, P. E. (Ed.), Chemistry and Biochemistry of Natural Waxes, Elsevier, New York 1976, pp. 147-200.

[18] Fallis, A. M., Smith, S. M., Can. J.Zool. 1964, 42, 723-730.

[19] Russell, C. B., Hunter, F. F., J. Med. Entomol. 2005, 42, 301-305.
[20] Williams, C. R., Kokkinn, M. J., Smith, B. P., J. Chem. Ecol. 2003, 29, 1889-1903.

[21] Allan, S. A., Bernier, U. R., Kline, D. L., J. Med. Entomol. 2006, 43, 225- 231 .

[22] Bernier, U. R., Kline, D. L., Schreck, C. E., Yost, R. A., Barnard, D. R., J. Am. Mosq. Control Assoc. 2002, 18, 186-195.

[23] Bernier, U. R., Kline, D. L., Posey, K. H., in: Debboun, M., Frances, S. P., Strickman, D. (Eds.), Insect Repellents Principles, Methods, and Uses, CRC Press, Boca Raton, FL 2006, pp. 85-86.

[24] Weldon, P. J., Carroll, J. F., in: Debboun, M., Frances, S. P., Strickman, D. (Eds.), Insect Repellents Principles, Methods, and Uses, CRC Press, Boca Raton, FL 2006, pp. 51-64.

[25] Patel, R. N., Hou, C. T., Laskin, A. I., Derelanko, P., Felix, A., Appl. Environ. Microbiol. 1979, 38, 219-223.

[26] Gervais, T. R., Carta, G., Gainer, J. L., Biotechnol. Prog. 2000, 16, $208-212$

[27] Baldasseroni, A., Bavazzano, P., Buiatti, E., Lanciotti, E., Lorini, C., Toti, S., Biggeri, A., Int. Arch. Occup. Environ. Health 2003, 76, $260-266$

[28] Krückert, K., Flachsbarth, B., Schulz, S., Hentschel, U., Weldon, P. J., J. Nat. Prod. 2006, 69, 863-870.

[29] Puri, S. N., Mendki, M. J., Sukumaran, D., Ganesan, K., Prakash, S., Sekhar, K., J. Med. Entomol. 2006, 43, 207- 213.

[30] DeMilo, A. B., Lee, C.-J., Levi, V. A., Moreno, D. S., J. Entomol. Sci. 1997, 32, 245-256.

[31] Nicolaides, N., Kellum, R. E., J. Am. Oil Chem. Soc. 1965, 42, 685 690 